\title{
Effects of Short Rest Intervals on Body Composition, Hormonal Response and Strength During High-Load Resistance Trainings
}

\author{
Jonathan Fusi ${ }^{1}$, Giorgia Scarfo ${ }^{1 *}$, Alessandro Giovannelli ${ }^{1}$, Tommaso Cuspolici ${ }^{1}$, Muzaffar \\ Asomov $^{1}$, Davide Maria Cammisuli ${ }^{2}$, Augusto Innocenti ${ }^{1}$ and Ferdinando Franzoni ${ }^{1}$ \\ ${ }^{1}$ Department of Clinical and Experimental Medicine, University of Pisa, Italy \\ ${ }^{2}$ Department of Psycholgy, Catholic University of the Sacred Heart, Milan, Italy \\ *Corresponding author: Giorgia Scarfo, Department of Clinical and Experimental Medicine, University of Pisa, Italy
}

ARTICLE INFO

Received: 陆 June 22, 2021

Published: 慧 July 09, 2021

Citation: Jonathan Fusi, Giorgia Scarfo, Alessandro Giovannelli, Tommaso Cuspolici, Muzaffar Asomov, et al., Effects of Short Rest Intervals on Body Composition, Hormonal Response and Strength During High-Load Resistance Trainings. Biomed J Sci \& Tech Res 37(1)-2021. BJSTR. MS.ID.005946.

Abbreviations: TEST: Testosterone; GH: Growth Hormone; IGF1: Insulin-like Growth Factor-1; CUS: University Sports Center; BL : Baseline; DHEA: Dehydroepiandrosterone; DHEA-S: Dehydroepiandrosterone-Sulfate; DHT: Dihydrotestosterone; CORT: Cortisol; IGF-1: Insulin-Like Growth Factor; ACTH: Adrenocorticotropic Hormone; LH: Luteinizing Hormone; ELISA: Enzyme-Linked Immunosorbent Assay; SD: Standard Deviation

\section{ABSTRACT}

Background: The modulation of rest intervals in resistance training could induce different muscular tissue and hormonal response. The aim of the present pilot study was to the long-term adaptations induced by short rest intervals in high-load resistance training.

Methods: Ten healthy untrained subjects (age 25.6 \pm 4.7 years) underwent a 3-weekly 2 -month high-load ( $>90 \%$ of RM) resistance-training program with short rest intervals between stets $(<90 \mathrm{sec})$ and low recovery time between exercises $(120 \mathrm{sec})$. Every exercise session was structured in order to train the entire body (bench press, pulley, leg press, curl with dumbbell, french press, hummer curl, hummer curl with relaxation and pull ups) such as to move close to a 'classical' training tab. Anthropometric parameters, strength and hormonal responses were taken in all the subjects before and after the training protocol.

Results: Training increased arm $(\mathrm{P}<0.05)$, thigh $(\mathrm{P}<0.05)$ and chest $(\mathrm{P}<0.01)$ circumferences, while decreased waist circumference $(\mathrm{P}=\mathrm{n} . \mathrm{s})$ with respect to baseline. Strength on RM was increased on bench press $(\mathrm{P}<0.05)$, pulley $(\mathrm{P}<0.05)$ and leg press $(\mathrm{P}<0.01)$ exercises. Blood analyses showed a decrease of IGF1 $(\mathrm{P}=\mathrm{n} . \mathrm{s})$ and cortisol $(\mathrm{P}<0.05)$, while testosterone $(\mathrm{P}=\mathrm{n} . \mathrm{s})$, DHT $(\mathrm{P}<0.01)$ and $\mathrm{GH}(\mathrm{P}<0.001)$ were increased. In addition, we observed an increase of TEST/CORT ratio $(\mathrm{P}<0.05)$.

Conclusion: The results of the present study showed that a single training program with short rest intervals associated to high-load strength exercises could induce an increase in both muscular mass and strength.

Keywords: Short Rest Periods; Resistance Training; Testosterone; GH; Strength Training

\section{Introduction}

Resistance training induces a wide range of physiological adaptations, including an increase of muscle strength and hypertrophy. In particular, mechanical stimulus can trigger muscle hypertrophy in cooperation with the neuroendocrine system, which plays a fundamental role in the tissue remodeling [1]. The process of hypertrophy involves a proportionate increase in the accretion of the contractile proteins, actin and myosin, as well as of other structural proteins [2]. As reported by many studies, the physical and hormonal adaptations in response to resistance training depend from the same type of training. As the intensity of resistance exercise increases (resulting in increased activation of fast-twitch muscle fibers), a greater emphasis is placed on 
mechanical stress [3], In contrast, high-volume programs (greater number of repetitions concomitant with the use of short rest intervals) elicit greater metabolic stress [2]. Among the different hormonal adaptations induced by physical exercise, Testosterone (TEST), Growth Hormone (GH) and Insulin-like Growth Factor-1 (IGF1) are the most studied hormones. The expression of these hormones is related to the intensity [4], rest interval and volume of the exercise [5]. The classic model of periodization, the systematic process based on the altering of one or more training program [6], is characterized by a high initial training volume and low intensity, and, with the progress of training, volume decrease and intensity gradually increase [2].

As concern rest periods, it was observed that exercise with long versus short rest periods (2-5min vs $30-40$ s) induce a greater strength increase [7]. In contrast, according to other studies, low intensity, high volume and moderate rest periods (2-3min) training program have been demonstrated to induce an increase of hypertrophy $[8,9]$. However, a few methodological limitations, including program design and hypertrophy assessment, raise several questions concerning the efficacy of each training program. Moreover, the hormonal response associated with these training programs, remain unclear. The aim of the present pilot study was to investigate the effects of a specific resistance training program with short rest periods on the physiological adaptations of muscle strength and hypertrophy.

\section{Methods}

\section{Experimental Design}

Prior to the onset of the study, the participants were required to complete a 2-weeks base training program. Assessment of body circumferences (arm, thigh, chest and waist), anthropometric parameter (weight, high, BMI), and strength were measured preand post-training. Subsequently, participants completed 8-week (3 session of workout a week) of two training resistance period: 6 weeks with a hypertrophy and strength exercise program and the last 2 weeks with 3 sessions of only strength exercise program to avoid phenomena of adaptation. The participants attended University Sports Center (CUS) of Pisa, under the direct supervision of certified strength and conditioning specialists. Blood samples were collected on day 1 of week 3 (the first week of training after the base training period) and week 10 .

\section{Participants}

Ten healthy men (age 25.6 \pm 4.7 years, weight $82 \pm 11.2 \mathrm{~kg}$; height $176.4 \pm 14.2 \mathrm{~cm}$ ) with sedentary lifestyle agreed to participate in this study. Following an explanation of all procedures, risks, and benefits, each participant provided his informed consent to participate in the study. The investigation was approved by the ethics committee of "Area Vasta Nord Ovest" for clinical experimentation (CEAVNO) of the University of Pisa, and all participants signed a written consensus for the study. All participants were free of any physical limitations (determined by medical history questionnaire) and had not been previously participating in resistance training for at least 2 years. Participants were instructed to maintain their normal eating habits throughout the course of the study. Kilocaloric and macronutrient intake were monitored via weekly food diaries.

\section{Preparatory Phase of Training}

The participants completed a 2 weeks of a base resistance training protocol. This time was necessary to familiarize participants with all the exercises. This phase encompassed a total of six workouts: three workouts (Monday, Wednesday, and Friday) during the first week and three workouts (Monday, Wednesday, and Friday) during the second week. The purpose of the preparatory training program was to instruct proper lifting technique, familiarize participants with all exercises, and ensure the participants initiated the study with a comparable training base. During this phase, the exercises, and their order, volume (8-10 reps x $60 \%$ of RM) and rest periods (150sec) were identical for all the participants.

\section{Strength Testing}

Strength in the bench press, pulley and leg press was assessed pre- and post-training. A general warm up consisting of riding a cycle ergometer and abs exercise such as bicycle crunch and traditional crunch for 5 min. Subsequently, the general warm up was followed by specific warm up for 10 smith machine, 10 leg press and 10 pulley with $20 \%$ of RM each other. The determination of one repetition maximum (1RM) was executed as described by Mangine et al.10. 1RM was estimated for the other exercise: curl with dumbbell, french press (dumbbell), hummer curl, hummer curl with relaxation, pull-ups pre- and post-training.

\section{Resistance Training Intervention}

Participants reported to the Pisa University Sports Centre (CUS) three times per week (M/W/F) to complete their first assigned training program. Briefly, the first training program was structured to increase strength and hypertrophy. Number of series and repetitions change for each exercise, but the basic concept that linked the structure of the training program is that every repetition must be carried out as if it were the last, bringing muscle exhaustion. This was achieved by working with a weight that induced this condition. The participants performed at $87-100 \%$ of $1 \mathrm{RM}$. The second training program was structured to increase strength. On Monday and Friday, participants performed pyramidal system to rise and fall for smith machine, leg press and pulley, starting from $92 \%$ until $100 \%$ of $1 \mathrm{RM}$. On Wednesday, participants performed $3 \times 1$ at $100 \%$ of $1 \mathrm{RM}$ about smith machine, leg press and pulley plus 
$1 \mathrm{xmax}$ with $50 \%$ of RM and with a weight that allows the execution of 3 series to 6 reps for triceps and hummer curl. The gradual increase in weight for every exercise was calculated in order to obtain the muscular exhaustion before the completion of reps. The weight of exercise was increased in every training session. Training intensity was determined from 1RM testing (smith machine, leg press and pulley) and estimated 1RM (all other exercises) [10]. For each training program, the rest period between each series was 90 $\mathrm{s}$, while the rest period between each exercise was $2 \mathrm{~min}$. Only in the step between upper and lower body recovery, rest period was 5 min. Both training programs had an average duration of $70 \pm 25 \mathrm{~min}$

\section{Blood Sampling}

Blood samples were obtained at two time points: baseline (BL) (after the two weeks of preparatory phase) and at the end of the resistance training intervention (E). Each blood samples were obtained on Monday. Participants were examined at 07:45AM in a quiet, air-conditioned room with temperature maintained at 22-24 ${ }^{\circ} \mathrm{C}$. After introduction of an indwelling cannula (Abbocath $20 \mathrm{G}$ ) into the left antecubital vein, the subjects were allowed to rest in a supine position for a $15 \mathrm{~min}$ equilibration period. All blood samples were collected into two Vacutainer ${ }^{\circledR}$ tubes, one containing no anticlotting agent $(6 \mathrm{~mL})$ and the second containing EDTA $(6 \mathrm{~mL})$. A small aliquot of whole blood was removed and used for determination of hematocrit and hemoglobin concentrations and routine parameters such as HDL, LDL, and total cholesterol, triglycerides and glucose. The blood in the first tube was allowed to clot at room temperature for $30 \mathrm{~min}$ and subsequently centrifuged at $3000 \mathrm{~g}$ for $15 \mathrm{~min}$ along with the remaining whole blood from the second tube. The resulting plasma and serum were placed into separate microcentrifuge tubes and frozen at $-80{ }^{\circ} \mathrm{C}$ for later analysis.

\section{Biochemical Analysis}

Circulating concentrations of testosterone (TEST), dehydroepiandrosterone (DHEA), dehydroepiandrosterone-sulfate (DHEA-S), dihydrotestosterone (DHT), cortisol (CORT), insulin-like growth factor (IGF-1), growth hormone (GH), adrenocorticotropic hormone $(\mathrm{ACTH})$, and Luteinizing hormone ( $\mathrm{LH})$ were assessed via enzyme-linked immunosorbent assay (ELISA) and a spectrophotometer using commercially available kits. To eliminate the inter assay variance, all samples for each assay were thawed once and analyzed in duplicate in the same assay run by a single technician.

\section{Statistical Analysis}

The values are expressed as mean \pm standard deviation (SD).
The normality of distribution of the data was examined with the Kolmogorov-Smirnov test. To examine differences in the endocrine response to exercise from $\mathrm{WK} 3$ to $\mathrm{WK} 10$, a repeated measure analysis of variances (ANOVA) was calculated for each parameter. Bonferroni post-hoc tests were used when the interaction was significant. Quantitative chances of higher or lower differences were evaluated qualitatively as follows: $<1 \%$, almost certainly not; $1-5 \%$, very unlikely; $5-25 \%$, unlikely; $25-75 \%$, possible; $75-95 \%$, likely; 95-99\%, very likely; >99\%, almost certain. If the chances of having higher or lower values than the smallest worthwhile difference were both $>5 \%$, the true difference was assessed as unclear. Pearson's correlation coefficients were calculated to establish the respective relationships between the changes of all measured variables. The analyses were conducted using the software Prism 4.0 (GraphPad Software Inc., San Diego, CA, USA). Statistical significance was established at the $\mathrm{P}<0.05$ level.

\section{Results}

\section{Anthropometric and Morphological Changes}

After the anthropometric evaluation, the subjects' BMI did not significantly differ before and after training program (Figure 1). Arm $(29.01 \pm 1.67$ vs $31.12 \pm 1.16 \mathrm{~cm}, \mathrm{p}<0.05)$, thigh $(53.25 \pm 2.11$ vs $55.08 \pm 2.01 \mathrm{~cm}, \mathrm{p}<0.05)$ and chest $(93.01 \pm 2.85$ vs $98.11 \pm 3.31 \mathrm{~cm}$, $\mathrm{p}<0.01$ ) circumferences were significantly increased after the training program (Figure 2). In contrast, the waist circumference was decreased $(78.51 \pm 3.30$ vs $77.86 \pm 2.44 \mathrm{~cm}, p=n . s$, Figure 2$)$. An increase of free mass ( $83.64 \pm 3.86$ vs $85.33 \pm 2.67 \%$; $p<0.05$ ), with a decrease of free fat mass (17.36 \pm 3.96 vs $14.67 \pm 3.67 \%$; $<<0.05$; ) and an increase of Total Area on upper (TAA $58.09 \pm 4.30$ vs $66.12 \pm 5.50$; $\mathrm{P}<0.01$ ) and lower (TLA $177.06 \pm 29.92$ vs $195.49 \pm 19.70 ; \mathrm{P}<0.01$ ) body were observed after training program. In particular, an increase of the muscular area was observed at the end of training program in the upper (AMA $49.60 \pm 2.73$ vs $57.89 \pm 3.97$; $<<0.01$ ) and lower (LMA $153.56 \pm 25.14$ vs $172.56 \pm 16.18$; $\mathrm{P}<0.01$ ) body part. In contrast, a decrease of the fat area was evidenced at the end of training program on upper (AFA $8.49 \pm 1.58$ vs $8.24 \pm 1.54$; $\mathrm{P}=\mathrm{n} . \mathrm{s}$ ) and lower (LFA $23.51 \pm 4.79$ vs $22.92 \pm 3.51$; $\mathrm{P}=\mathrm{n} . \mathrm{s}$ ) body part. As concern strength parameters, the 1RM of every exercise was increased after protocol intervention, particularly with the use of smith machine, pulley and leg press, which produced an increase versus pre-training of $48.95 \%(\mathrm{P}<0.05), 37.43 \%(\mathrm{p}<0.05)$ and $88.73 \%(\mathrm{p}<0.01)$, respectively (Figure 3$)$. Finally, regarding the hummer with relaxation exercise, we observed a significant increase of total work ( $198 \pm 18$ vs $264 \pm 16.97$; $\mathrm{P}<0.05$ ). 


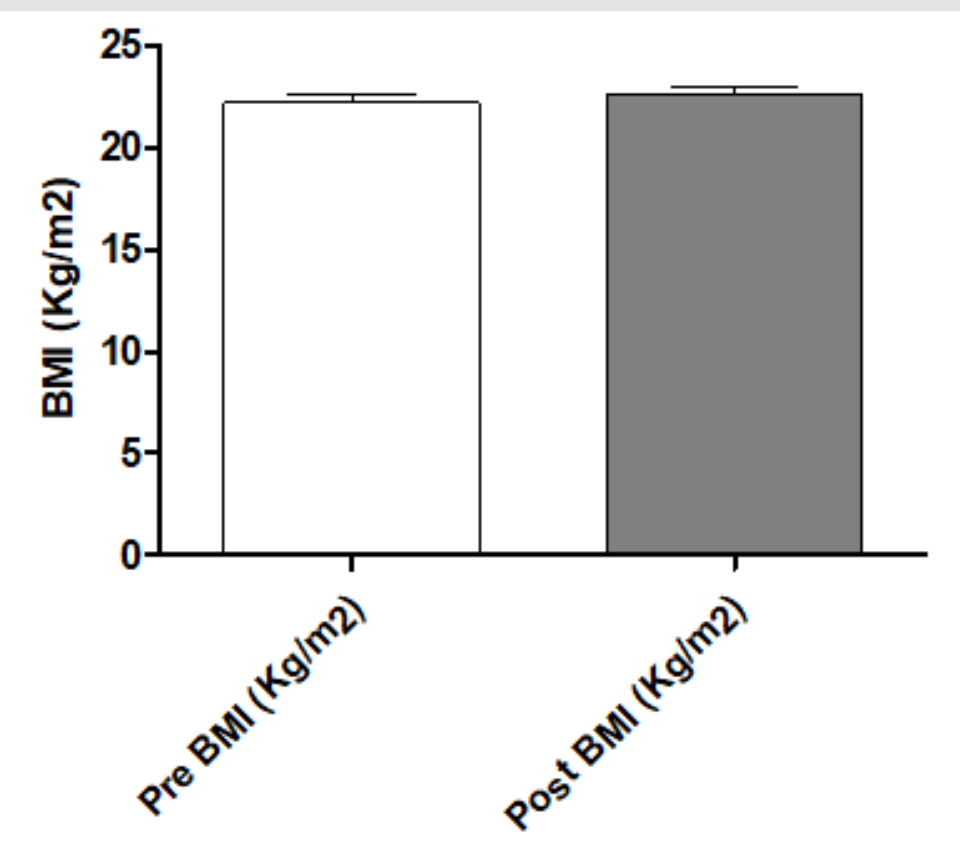

Figure 1: Subjects' BMI $(\mathrm{Kg} / \mathrm{m} 2)$ before and after training program. Ten men between the ages of 21 and 33 with sedentary lifestyle underwent resistance training for at least 2 years described in the Methods section. At the end the anthropometric evaluations were made. The data are expressed as level of BMI $(\mathrm{Kg} / \mathrm{m} 2)$. These data represent the men \pm SEM of pre- and post-training program.

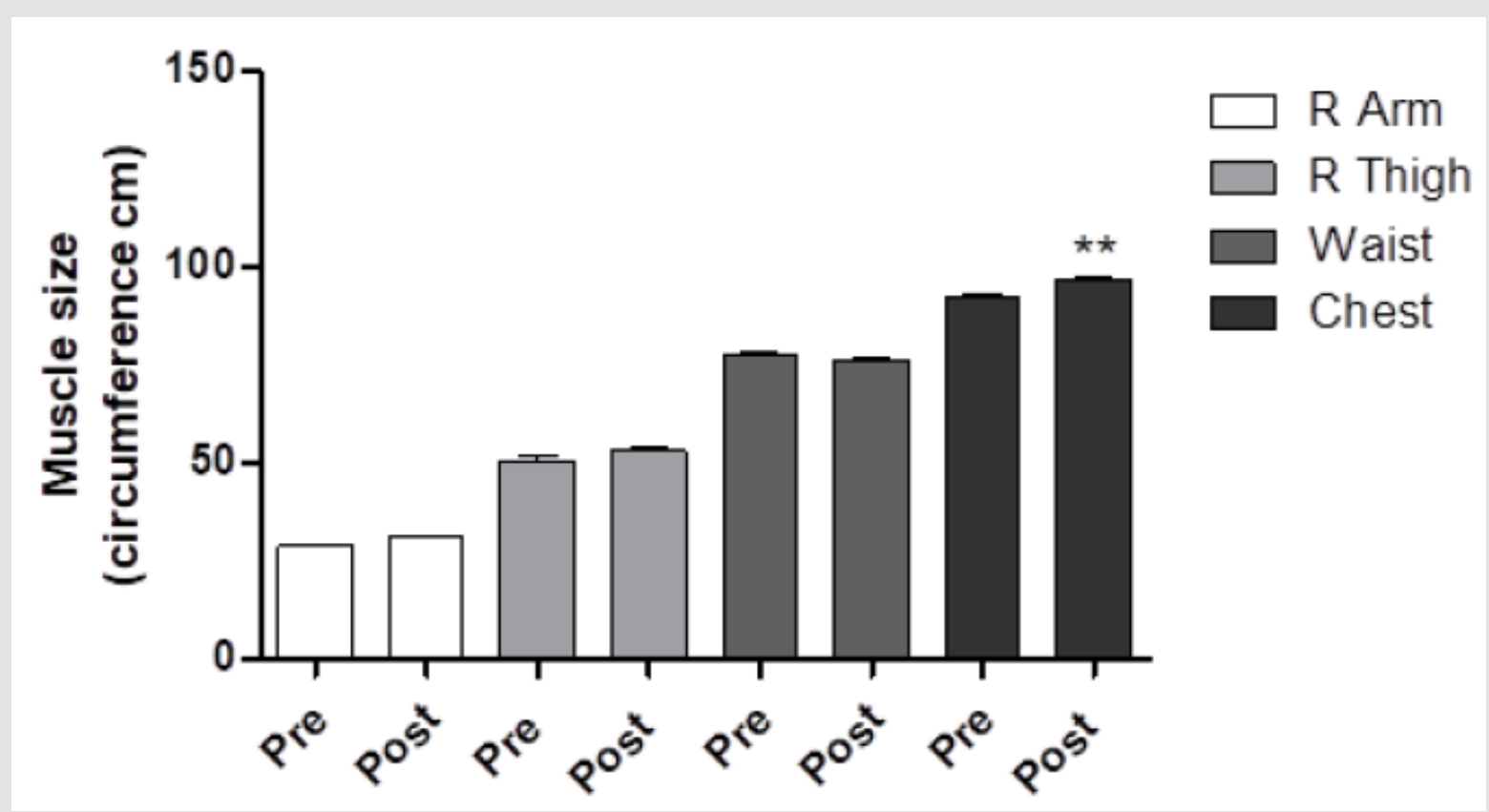

Figure 2: Subjects' muscle size $(\mathrm{cm})$ before and after training program. Ten men between the ages of 21 and 33 with sedentary lifestyle underwent resistance training for at least 2 years described in the Methods section. At the end, the anthropometric evaluations were made. The data are expressed as circumference $(\mathrm{cm})$ of $\mathrm{R}$ arm, $\mathrm{R}$ thigh, waist and chest size before and after training. These data represent the men \pm SEM of pre- and post-training program. $P<* * 0,01$ vs pre-training program. 


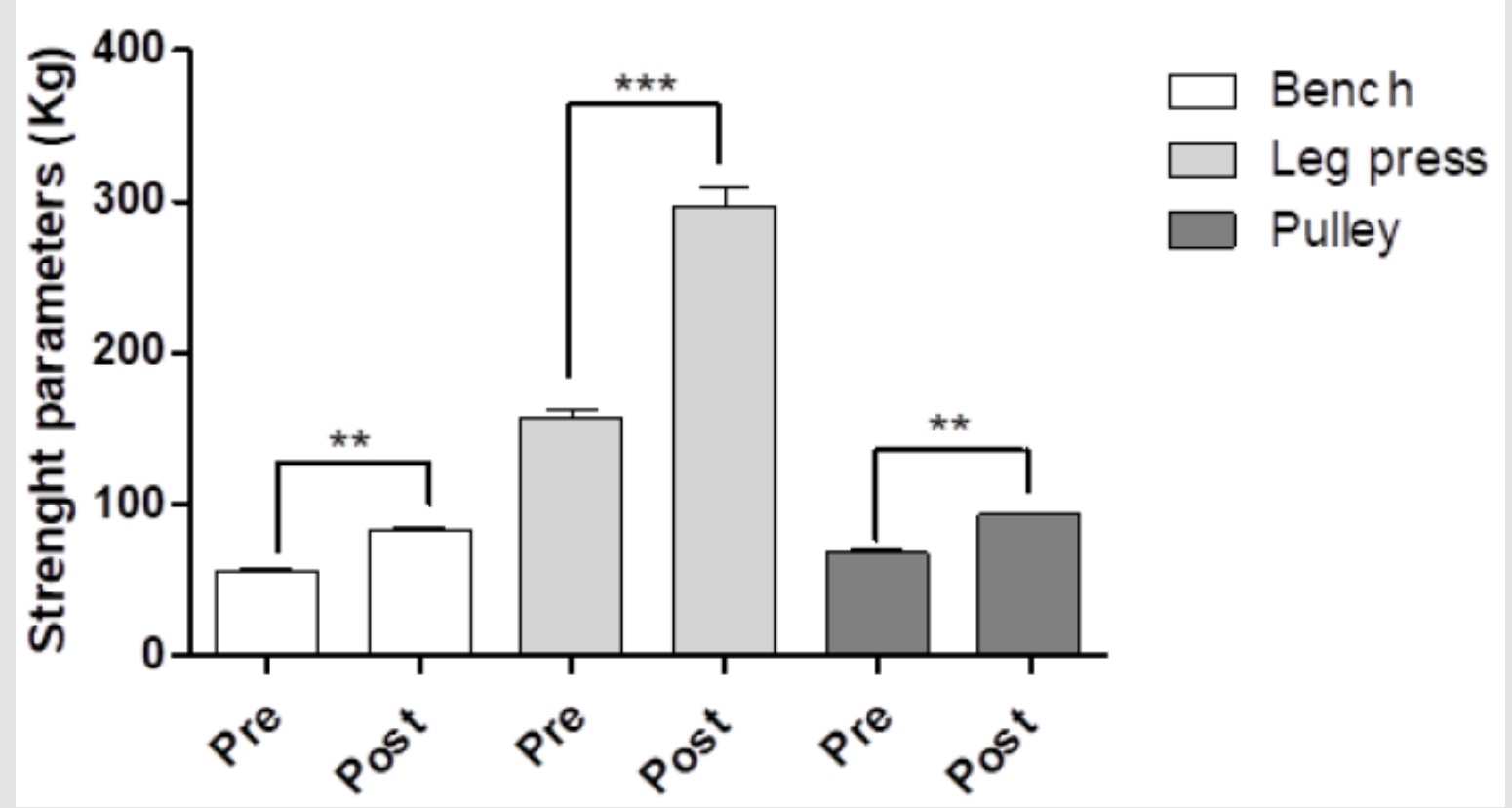

Figure 3: Strength parameters $(\mathrm{Kg})$ before and after training program. Ten men between the ages of 21 and 33 with sedentary lifestyle underwent resistance training for at least 2 years described in the Methods section. At the end, the strength parameters evaluations were made. The data are expressed as $\mathrm{Kg}$ of bench, leg press and pulley before and after training. These data represent the men \pm SEM of pre- and post-training program. ${ }^{* *} \mathrm{P}<0.01$, ${ }^{* * *} \mathrm{P}<0.001$ vs pre-training program.

\section{Biochemical and Hormonal Parameters}

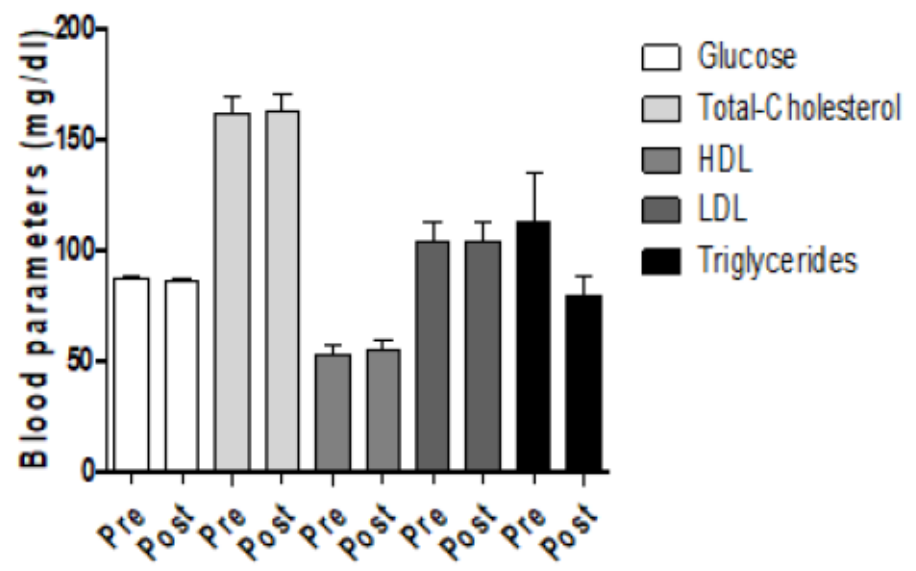

b

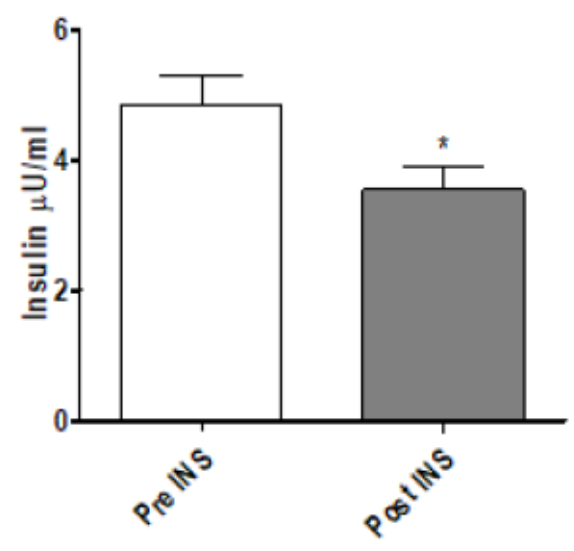

Figure 4: Blood parameters (mg/ dl) before and after training program. Ten men between the ages of 21 and 33 with sedentary lifestyle underwent resistance training for at least 2 years described in the Methods section. At the end, the blood parameters evaluations were made.

a) The data are expressed as $\mathrm{mg} / \mathrm{dl}$ of glucose, total-cholesterol, HDL, LDL, triglycerides

b) and insulin $\mu \mathrm{U} / \mathrm{ml}$ before and after training.

These data represent the men \pm SEM of pre- and post-training program. ${ }^{*} \mathrm{P}<0.05$ vs pre-training program. 
Blood parameters in response to training, during W3 and W10 are shown in Figure 4. As concern the lipid profile, the training program produced an increase of total cholesterol $(145.21 \pm 18.43$ vs $147.62 \pm 22.56 \mathrm{mg} / \mathrm{dL}$; $\mathrm{P}=$ n.s; Figure $4 \mathrm{a}$ ), with an increase of HDL (53.21 \pm 10.04 vs $55.42 \pm 11.39 \mathrm{mg} / \mathrm{dL}$; P=n.s.; Figure 4a) and a decrease of LDL $(89.62 \pm 17.11$ vs $85.21 \pm 21.05 \mathrm{mg} / \mathrm{dL} ; \mathrm{P}<0.05$; Figure 4a). The Total Cholesterol-HDL ratio was diminished significantly at the end of the training protocol $(2.83 \pm 0.63$ vs $2.76 \pm 0.60 ; P=n . s)$; this decrease was observed even in the LDL-HDL ratio $(1.76 \pm 0.51$ vs $1.61 \pm 0.50 ; \mathrm{P}<0.05)$. In addition, there was a decrease in the level of triglycerides $(70.51 \pm 20.16$ vs $60.75 \pm 6.79$; $\mathrm{P}<0.001$; Figure 4 a). Finally, a decrease of glucose $(85.4 \pm 5.57$ vs $84.8 \pm 5.19 \mathrm{mg} /$ dL; $\mathrm{P}=$ n.s.; Figure $4 \mathrm{a})$ and insulin $(5.29 \pm 1.96$ vs $3.73 \pm 1.57 \mu \mathrm{U} /$ $\mathrm{mL} ; \mathrm{P}<0.01$; Figure $4 \mathrm{~b}$ ) was evidenced after the training program. Regarding hormonal parameters (Figure 5), TEST level was increased at $\mathrm{W} 10(+1.13 \% \mathrm{P}=$ n.s. ; Figure $5 \mathrm{a})$, as well as DHT $(+18.78 \% \mathrm{P}<0.01$; Figure $5 \mathrm{~b})$ and $\mathrm{GH}(+52.88 \% \mathrm{P}<0.001$; Figure 5c). CORT $(-7.95 \% \mathrm{P}<0.05$; Figure $5 \mathrm{~d})$, IGF1 $(-3.23 \% \mathrm{P}<0.05$; Figure 5e), DHEA $(-10.67 \% \mathrm{P}<0.01$; Figure 5 f), DHEA-S (-2.68\%; $\mathrm{P}=\mathrm{n} . \mathrm{s}$; Figure $5 \mathrm{~g}), \mathrm{LH}(-5.90 \% \mathrm{P}<0.05$; Figure $5 \mathrm{~h})$, ACTH $(-5.58 \% \mathrm{P}<0.05$; Figure $5 \mathrm{i}$ ) were decreased at the end of the training program. In addition, as a direct result, we observed an increase of TEST/CORT ratio $(+3 \% \mathrm{P}<0.05)$. This result is in line with the anabolic effect induced by the resistance training and confirmed by the increase of free fat mass.

\section{Discussion}

Two features are remarkable in our protocol:

1) The recovery time used during training sessions (90 seconds);

2) The onset of an anabolic condition.

Considering them, there was not only a great strength and hypertrophy rise, but also an important metabolic and hormonal adjustment. According to literature data, many resistance training protocols have been already demonstrated to increase strength and hypertrophy, but they differ as far as concerned the recovery time used [11-14]. For example, in terms of chronic adaptations, De Salles, et al. [15] suggested that 3-5 minute rest periods between sets can produce greater increases in absolute strength. Also Schoenfeld et al. (2016) argued that a longer inter-set rest period could better enhance muscle Strength and hypertrophy [16]. The other remarkable feature of our protocol is the significant fat free mass increase after only 8-week training: in fact, the increase of armchest-thigh circumferences and the waist circumference decrease are usually observed in aerobic trainings programs or in longer resistance training ones [17]. It has also to be noticed that, in our study, participants performed a high-load/ low volume workouts as against other protocols that suggested exactly the opposite in order to obtain a protein accretion. For example, Burd et al. (2010) argued that low load/high volume resistance training is more effective in increasing muscle protein synthesis [18]. In the same way, other studies have demonstrated that the low load resistance, performed to muscular failure, induced a similar myofibrillar accretion [19]. From a metabolic point of view, the lipid profile improvement is huge, considering our 8-week high -load intensity training (87$100 \%$ of $1 \mathrm{RM}$ ) : some studies even suggest that resistance training doesn't affect the lipid profile [20,21], while other authors argue that only low/moderate intensity resistance training can modulate LDL, triglycerides and HDL in a positive way [22].

Both the marked enhancement in muscle strength and the better lipid profile could result from the anabolic adaptations that happened in the present study (TEST-DHT-GH increase / IGF1-ACTHDHEA-CORT decrease): in particular, testosterone administration is known to reduce insulin resistance, total cholesterol, LDL cholesterol and triglycerides and improve anthropometric parameters [23]. As far as muscle strength concerned, any increase can be explained by the TEST/CORT ratio increase. The TC ratio may indicate the anabolic/catabolic environment of an organism due to their roles in protein synthesis and protein degradation, respectively [24]. Other resistance training protocols, indeed, have shown a decrease of TEST levels caused by an increase of Androgenic Receptors on muscle cell membranes that recruit TEST to enhance strength [25]. This difference about TEST level is probably due to the different exercise training program we used. Regarding the rest period influence on hormonal parameters, Scudese et al. (2016) stated that although both short and long rest periods enhance acute testosterone values, the longer rest promotes a long-lasting elevation for TEST [26]. In this case, the authors evaluated hormonal parameters after 30 min maximum. In contrast, we measured them after 2 days, in order to observe the long-term adaptation. The anabolic condition achieved in our study is also confirmed by the DHT rise and the DHEA-s decrease. Dyhidrotestosterone, a free TEST intermediate synthetized by $5 \alpha$-reductase is the most active TEST metabolite thanks to a higher receptor activity and a lower dissociation rate compared to TEST. It has been showed that 12 weeks of resistance training significantly restored, in older man, free testosterone, and DHT to levels seen in young subjects [27].

DHEA-S, instead, is a TEST precursor [28] and so its decrease correlates with increased TEST levels. Conflicting data concerning DHEA response after exercise have been reported: studies reported its increase after resistance exercise [29] or any change after training [30]. On the other hand, Riechman et al. (2004) observed a small DHEA concentration decreased after 10 -week resistance training in men and women [31]. In all these studies, the evaluation has been conducted in acute, while we performed the analysis after 48 hours. In addition, these authors have used training protocols with different load, intensity and rest periods making difficult the comparison among them. In our protocol, the anabolic process 
activation is also supported by the evaluation of serum GH. It is a metabolic stressor related to body growth, hypertrophy and regulation of metabolism and its release seems to be dependent to rest intervals between sets [32]. Bottaro et al. (2009) observed that GH increases more significantly with short rest intervals (30s) than long-rest ones (60 or 120s) [33]. Similar results were obtained by Fink, et al. [34]. Even if we used similar short-rest intervals (90s), unlike them, who used low loads, our participants performed a high-load (87<>100\%) with short rest period and medium repetitions. Moreover, the GH-hypertrophy effect is regulated by IGF1, but it has been shown that its local expression in skeletal muscle appears to act independently of any change in serum GH or IGF-1 [35]. Therefore, free fat mass increase and hypertrophy could be related to a local IGF-1 increase, since we did not observe a significant serum IGF-1 change.

In our hands, no significant changes in LH serum level. LH stimulates intratesticular TEST secretion [36] but its response to physical activity has been rarely investigated. Consistent with our data, Taipale et al. (2017) have observed no alteration of serum LH after resistance training even though they used lower loads than ours [37]. Of note, both cortisol and ACTH serum levels decreased in our study, therefore favouring the TEST/CORT ratio enhancement. This is a significant result considering the fact that cortisol is usually involved in the inflammatory response to exercise becoming an important parameter of the overtraining syndrome [38]. In this sense, Izquierdo et al. (2009) showed how cortisol level can increase after resistance trainings with a consequent high release of pro-inflammatory cytokines [39]. Probably, in our protocol, cortisol reduction depends on our high load/low volume training program: in fact, its greatest acute elevation has been demonstrated to occur in different protocols from our workouts, such as medium -load, high-volume protocols, usually preferred by body builders [40].

\section{Conclusion}

The aim of our study was to investigate the effects of 8 weeks of resistance protocol based on high load (over $87 \%$ RM), medium repetition, short rest periods between sets (90s) and short rest periods between exercises on physiological point of view. Overall, we observed a significant increase of strength, related to significant increase of DHT and a trend of increase of testosterone, the major responsible to strength increase. In addition, we observed an increase of free fat mass related to increase of GH and the ratio of testosterone cortisol. As concern the lipid profile, a decrease of cardiovascular risk factors typical of aerobic exercise were observed. All these adaptations could be related to the use of short rest periods with high load, which induce a not completely recovery as concern muscular (i.e. lactide acid restore) and heart rate. Herein, we showed that a high load with short rest periods could induce typical adaptations of strength and hypertrophy training, as well as some typical adaptations of aerobic workouts. All authors have read and agreed to the final version of the manuscript.

\section{Conflict of Interest}

The authors declare that the research was conducted in the absence of any commercial or financial relationships that could be construed as a potential conflict of interest.

\section{References}

1. Kraemer WJ, Ratamess NA (2005) Hormonal responses and adaptations to resistance exercise and training. Sports Med 35(4): 339-361.

2. Kraemer WJ, Adams K, Cafarelli E, Dudley GA, Dooly C, et al. (2002) American College of Sports Medicine position stand. Progression models in resistance training for healthy adults. Med Sci Sports Exerc 34(2): 364-380.

3. Henneman E, Somjen G, Carpenter DO (1965) Functional significance of cell size in spinal motoneurons. J Neurophysiol 28: 560-580.

4. Kraemer WJ, Marchitelli L, Gordon SE, Harman E, Dziados JE, et al. (1990) Hormonal and growth factor responses to heavy resistance exercise protocols. J Appl Physiol 69(4): 1442-1450.

5. West DW, Kujbida GW, Moore DR, Atherton P, Burd NA, et al. (2009) Resistance exercise-induced increases in putative anabolic hormones do not enhance muscle protein synthesis or intracellular signalling in young men. J Physiol 587(21): 5239-5247.

6. Stone MH, Potteiger JA, Pierce KC, Proulx CM, O Bryant HS, et al. (2000) Comparison of the effects of three different weight-training programs on the one repetition maximum squat. J strengh Cond Res14(3): 332-327.

7. Ahtiainen JP, Pakarinen A, Alen M, Kraemer WJ, Häkkinen KJ (2005) Short vs. long rest period between the sets in hypertrophic resistance training: influence on muscle strength, size, and hormonal adaptations in trained men. Strength Cond Res 19(3): 572-582.

8. Cormie P, McCaulley GO, Triplett NT, McBride JM (2007) Optimal loading for maximal power output during lower-body resistance exercises. Med Sci Sports Exerc 39(2): 340-349.

9. Linnamo V, Pakarinen A, Komi PV, Kraemer WJ, Häkkinen K (2005) Acute hormonal responses to submaximal and maximal heavy resistance and explosive exercises in men and women. J Strength Cond Res 19(3): 5665671.

10. Mangine GT, Hoffman JR, Gonzalez AM, Townsend JR, Wells AJ, et al. (2015) The effect of training volume and intensity on improvements in muscular strength and size in resistance-trained men. Physiol Rep 3(8): e12472.

11. Crewther B, Keogh J, Cronin J, Cook C (2006) Possible stimuli for strength and power adaptation: acute hormonal responses. Sports Med 36(3): 215-238.

12. Willardson JM (2006) A brief review: Factors affecting the length of the rest interval between resistance exercise sets. J Strength Cond Res 20(4): 978-984.

13. Cormie P, McCaulley GO, McBride JM (2007) Power versus strengthpower jump squat training: Influence on the load-power relationship. Med Sci Sports Exerc 39(6): 996-1003.

14. Linnamo V, Pakarinen A, Komi P V, Kraemer WJ, Häkkinen K (2005) Acute hormonal responses to submaximal and maximal heavy resistance and explosive exercises in men and women. J Strength Cond Res 19(3): 566571.

15. De Salles BF, Simão R, Miranda F, Da Silva Novaes J, Lemos A, et al. (2009) Rest interval between sets in strength training. Sport Med 39(9): 765777. 
16. Schoenfeld BJ, Pope ZK, Benik FM, Garrettm Hester, John Sellers, et al. (2016) Longer interest rest periods enhance muscle strength and hypertrophy in resistance-trained men. J Strength Cond Res 30(7): 1805-1812.

17. Alberga AS, Prud Homme D, Sigal RJ, Gary S Goldfield, Stasia Hadjiyannakis, et al. (2016) Does exercise training affect resting metabolic rate in adolescents with obesity? Appl Physiol Nutr Metab 42(1):15-22.

18. Burd NA, West DWD, Staples AW, Philip J Atherton, Jeff M Baker, et al. (2010) Low-load high volume resistance exercise stimulates muscle protein synthesis more than high-load low volume resistance exercise in young men. PLoS One 5(8): e12033.

19. Farup J, De Paoli F, Bjerg K, Riis S, Ringgard S, et al. (2015) Blood flow restricted and traditional resistance training performed to fatigue produce equal muscle hypertrophy. Scand J Med Sci Sport 25(6): 754 763.

20. Sallinen J, Pakarinen A, Fogelholm M, M Alen, J S Volek, et al. (2007) Dietary intake, serum hormones, muscle mass and strength during strength training in 49-73-year-old men. Int J Sports Med 28(12): 1070 1076.

21. Elliott KJ, Sale C, Cable NT (2002) Effects of resistance training and detraining on muscle strength and blood lipid profiles in postmenopausal women. Br J Sports Med 36(5): 340-344

22. Lira FS, Uchida MC, Zanchi NE, Nelo E Zanchi, Bruno Gualano, et al (2010) Low and moderate, rather than high intensity strength exercise induces benefit regarding plasma lipid profile. Diabetol Metab Syndr 2: 31.

23. Zitzmann M (2009) Testosterone deficiency, insulin resistance and the metabolic syndrome. Nat Rev Endocrinol 5(12): 673-681.

24. Hayes LD, Bickerstaff GF, Baker JS (2010) Interactions of cortisol, testosterone, and resistance training: Influence of circadian rhythms. Chronobiol Int 27(4): 675-705.

25. Bamman MM, Shipp JR, Jiang J, BA Gower, GR Hunter, et al. (2001) Mechanical load increases muscle IGF-I and androgen receptor mRNA concentrations in humans. Am J Physiol - Endocrinol Metab 280(3): E383-390.

26. Scudese E, Simão R, Senna G, Jakob L Vingren, Jeffrey M Willardson, et al. (2016) Long rest interval promotes durable testosterone responses in high-intensity bench press. J Strength Cond Res 30(5): 1275-1286.

27. Sato K, Iemitsu M (2015) Exercise and sex steroid hormones in skeletal muscle. J Steroid Biochem Mol Biol 145: 200-205.

\section{ISSN: 2574-1241}

DOI: 10.26717/BJSTR.2021.37.005946

Giorgia Scarfo. Biomed J Sci \& Tech Res

This work is licensed under Creative

Commons Attribution 4.0 License

Submission Link: https://biomedres.us/submit-manuscript.php
28. Collomp K, Buisson C, Lasne F, Collomp R (2015) DHEA, physical exercise and doping. J Steroid Biochem Mol Biol 145: 206-212.

29. Cadore EL, Lhullier FLR, Brentano MA, Eduardo Marczwski da Silva, Melissa Bueno Ambrosini, et al. (2008) Hormonal responses to resistance exercise in long-term trained and untrained middle-aged men. J Strength Cond Res 22(5): 1617-1624.

30. Heaney JLJ, Carroll D, Phillips AC (2013) DHEA, DHEA-S and cortisol responses to acute exercise in older adults in relation to exercise training status and sex. Age (Omaha) 35(2): 395-405.

31. Riechman SE, Fabian TJ, Kroboth PD, Ferrell RE (2004) Steroid sulfatase gene variation and DHEA responsiveness to resistance exercise in MERET. Physiol Genomics 17(3): 300-306.

32. Carter Su C, Schwartz J, Argetsinger LS (2016) Growth hormone signaling pathways. Growth Horm IGF 28: 11-15.

33. Bottaro M, Martins B, Gentil P, Wagner D (2009) Effects of rest duration between sets of resistance training on acute hormonal responses in trained women. J Sci Med Sport 12(1): 73-78.

34. Fink J, Kikuchi N, Nakazato K (2018) Effects of rest intervals and training loads on metabolic stress and muscle hypertrophy. Clin Physiol Funct Imaging 38(2): 261-268.

35. Arellanes Licea EC, Ávila Mendoza J, Ramírez Martínez EC, Eugenia Ramos, Nancy Uribe González, et al. (2018) Upregulation of GH, but not IGF1, in the hippocampus of the lactating dam after kainic acid injury. Endocr Connect 7(2): 258-267.

36. Huhtaniemi I (2018) Hormonal regulation of spermatogenesis: Mutant mice challenging old paradigms. Eur J Endocrinol 179(3): R143-R150.

37. Taipale RS, Kyröläinen H, Gagnon SS, Nindl B, Ahtiainen J, et al. (2018) Active and passive recovery influence responses of luteinizing hormone and testosterone to a fatiguing strength loading. Eur J Appl Physiol 118(1): 123-131

38. Cadegiani FA, Kater CE (2017) Hormonal aspects of overtraining syndrome: A systematic review. BMC Sports Sci Med Rehabil 9: 14.

39. Izquierdo M, Ibañez J, Calbet JAL, Ion Navarro-Amezqueta, Miriam González-Izal, et al. (2009) Cytokine and hormone responses to resistance training. Eur J Appl Physiol 107(4): 397-409.

40. Hakkinen K, Pakarinen A (1993) Acute hormonal responses to two different fatiguing heavy-resistance protocols in male athletes. J Appl Physiol 74(2): 882-827.

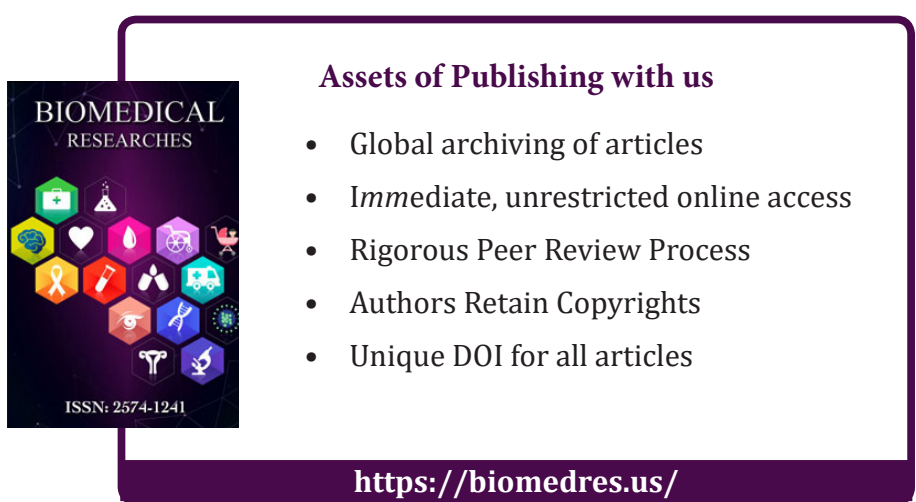

